\title{
Population attributable risks of oral cavity cancer to behavioral and medical risk factors in France: results of a large population-based case-control study, the ICARE study
}

Loredana Radoi ${ }^{12^{2 *}}$, Gwenn Menvielle ${ }^{3,4}$, Diane Cyr ${ }^{5,6}$, Bénédicte Lapôtre-Ledoux ${ }^{7}$, Isabelle Stücker ${ }^{1,8}$, Danièle Luce ${ }^{9,10}$, ICARE study group

\begin{abstract}
Background: Population attributable risks (PARs) are useful tool to estimate the burden of risk factors in cancer incidence. Few studies estimated the PARs of oral cavity cancer to tobacco smoking alone, alcohol drinking alone and their joint consumption but none performed analysis stratified by subsite, gender or age. Among the suspected risk factors of oral cavity cancer, only PAR to a family history of head and neck cancer was reported in two studies. The purpose of this study was to estimate in France the PARs of oral cavity cancer to several recognized and suspected risk factors, overall and by subsite, gender and age.

Methods: We analysed data from 689 oral cavity cancer cases and 3481 controls included in a population-based case-control study, the ICARE study. Unconditional logistic regression models were used to estimate odds ratios (ORs), PARs and $95 \%$ confidence intervals $(95 \% \mathrm{Cl}$ ).

Results: The PARs were $0.3 \%$ (95 \% Cl -3.9\%; +3.9 \%) for alcohol alone, $12.7 \%$ (6.9 \%-18.0 \%) for tobacco alone and $69.9 \%$ (64.4 \%-74.7\%) for their joint consumption. PAR to combined alcohol and tobacco consumption was $74 \%$ (66.5 \%-79.9\%) in men and $45.4 \%$ (32.7 \%-55.6 \%) in women. Among suspected risk factors, body mass index 2 years before the interview $<25 \mathrm{~kg} \cdot \mathrm{m}^{-2}$, never tea drinking and family history of head and neck cancer explained $35.3 \%$ (25.7\%-43.6 \%), $30.3 \%(14.4 \%-43.3 \%)$ and $5.8 \%(0.6 \%-10.8 \%)$ of cancer burden, respectively. About $93 \%$ (88.3 \%-95.6\%) of oral cavity cancers were explained by all risk factors, $94.3 \%(88.4 \%-97.2 \%)$ in men and only $74.1 \%(47.0 \%-87.3 \%)$ in women.

Conclusion: Our study emphasizes the role of combined tobacco and alcohol consumption in the oral cavity cancer burden in France and gives an indication of the proportion of cases attributable to other risk factors. Most of oral cavity cancers are attributable to concurrent smoking and drinking and would be potentially preventable through smoking or drinking cessation. If the majority of cases are explained by recognized or suspected risk factors in men, a substantial number of cancers in women are probably due to still unexplored factors that remain to be clarified by future studies.
\end{abstract}

Keywords: Oral cavity cancer, Population attributable risk, Tobacco, Alcohol, Tea, Body mass index

\footnotetext{
* Correspondence: Ioredana.radoi@inserm.fr

'INSERM UMRS 1018, Environmental Epidemiology of Cancer, Centre for research in Epidemiology and Population Health, 16 Avenue Paul Vaillant Couturier, 94807 Villejuif Cedex, France

${ }^{2}$ Oral Medicine and Oral Surgery Department, Paris Descartes University,

Montrouge, France

Full list of author information is available at the end of the article
} 


\section{Background}

Oral cavity cancer [1] is an important cause of morbidity and mortality in France, with approximately 6000 new cases and 1500 deaths each year [2] and incidence rates among the highest in the world [3]. In France, the incidence of oral cavity cancer has been strongly decreasing among men and strongly increasing in women [4]. Changes in the prevalence of the main risk factors, i.e. a decrease of daily smoking in men and an increase in women, and a decrease in alcohol drinking in both genders, are likely to partially explain these trends [4]. Despite the high incidence of oral cavity cancer in France, the role of tobacco smoking and alcohol drinking has been rarely studied [5-8], while other potential risk factors (e.g. family history of head and neck cancer (HNC), body mass index (BMI), personal medical history, tea consumption) were examined only in the present casecontrol study [9-11].

Population attributable risks (PARs) are useful tool to estimate the burden of risk factors in cancer incidence. Although several epidemiological studies examined the joint effect of tobacco and alcohol consumption and found evidence of an interaction on an additive [12] or multiplicative [13-18] scale, only few of them estimated the proportion of $\mathrm{HNC}$ that can be attributable to tobacco consumption alone, alcohol consumption alone, and their combined consumption [13, 15, 17]. However, the understanding of the independent and joint effects of tobacco and alcohol could have important implications for prevention. A pooled analysis within the International Head and Neck Cancer Epidemiology (INHANCE) Consortium [15] and a European case-control study [13] reported similar PARs of oral cavity cancer to tobacco and/or alcohol consumption ( $\mathrm{PAR}=63.7 \%$ and $61.3 \%$, respectively), but lower than that reported by one case-control study conducted in Latin America (PAR $=83.7 \%$ for oral cavity and oropharynx) [16]. PARs of HNC to tobacco and alcohol differed by gender (greater in men that in women), and by age (greater in older subjects than in younger subjects) in three studies $[13,15,19]$.

The few available studies on HNC related to alcohol and tobacco consumption which provided separate PARs of oral cavity cancer did not include French data, and none performed analysis on oral cavity cancers stratified by gender, age or anatomic location. However, concerning the carcinogenic effect of tobacco smoking and alcohol drinking, differences between oral subsites have been observed in some epidemiological studies [5, 20-25]. Moreover, among the other potential risk factors of $\mathrm{HNC}$, only the PAR of HNC to a family history of HNC has been estimated. It was low, in the order of $2 \%$ [26], although higher $(23.2 \%)$ in young adults with family history of early-onset cancer [19]. Estimates for PARs to other suspected risk factors were never provided.
In a previous analysis [5], we reported PARs for tobacco smoking and/or alcohol drinking for oral cavity subsites, but we did not assess the PAR due to the interaction between these factors, nor did we estimate PARs by gender and age. Also, it would be of interest to examine PARs of oral cavity cancer for other suspected risk factors, never provided previously.

Using data from the ICARE study, we conducted the present analysis to (i) estimate in France the proportion of oral cavity cancers attributable to the effect of tobacco smoking alone, alcohol drinking alone and to their joint effect; (ii) assess the PARs due to several potential risk factors previously observed in this study population (family history of HNC, personal history of oral candidiasis, low BMI and low tea consumption); (iii) examine differences in PARs, if any, by subsite, gender and age.

\section{Methods}

\section{Study population}

The study design, study population and data collection methods of the ICARE (Investigation of occupational and environmental CAuses of REspiratory cancers) study have been described in details elsewhere [27]. Briefly, the ICARE study is a multi-centre population-based casecontrol study on lung and HNC, carried out from 2002 to 2007 in 10 French administrative areas, covered by a general cancer registry.

The present analysis included only cases with oral cavity cancer (International Classification of Diseases $10^{\text {th }}$ revision [ICD-10] codes C01-C06 [1]) and all controls.

Cases eligibility criteria included histological confirmed primary malignant tumours of the oral cavity who were aged 75 or less at interview. Clinical and anatomopathological reports were reviewed to determine the topography and histological type of the tumours according to the International Classification of Diseases for Oncology [28]. Among the 1316 cases identified as eligible, 968 cases could be contacted, of which 792 (81.8\%) agreed to participate. Analyses were restricted to squamous cell carcinomas (772 cases). Controls were selected from the general population by random digit dialling, and were frequencymatched to the cases by age, gender and area of residence. Of the 4673 eligible controls, 4411 could be contacted, and 3555 (80.6\%) agreed to participate. All subjects gave their written informed consent for the participation in the study. The ICARE study was approved by the Institutional Review Board of the French National Institute of Health and Medical Research (IRB-Inserm, $\mathrm{n}^{\circ}$ 01-036), and by the French Data Protection Authority (CNIL, n 90120).

\section{Data collection}

Subjects were interviewed face-to-face with standardized questionnaires by trained interviewers. The questionnaire included information about socio-demographic 
characteristics, medical and family history, detailed tobacco, alcohol and tea consumption (quantity, duration, type of product, age at starting, time since cessation), and anthropometric measurements (height, weight at interview, two years before and at age 30). Ever smokers were defined as subjects who had smoked at least 100 cigarettes in their lifetime, or who had smoked at least one pipe, cigar or cigarillo per week for at least one year. Ever alcohol and tea drinkers were defined as subjects who had consumed at least one drink per month for at least one year. To ascertain the medical history, study participants were asked if, throughout their lives, they had ever had one or more diseases among those mentioned in a list, including oral candidiasis. To ascertain the family history of cancer, subjects were asked if their biological mother and father and their full brothers or sisters had ever had a cancer. If the answer was "yes", the subjects were asked to specify the type of cancer.

A summary version of the questionnaire was used when the subject was too sick to answer the complete questionnaire $(83$ cases $(10.8 \%)$ and 74 controls $(2.1 \%))$. This questionnaire did not include information about anthropometric measurements, family and medical history, and tea consumption. Therefore, these subjects were excluded from the present analysis that finally included 689 cases and 3481 controls.

\section{Statistical analysis}

Unconditional logistic regression models were used to estimate ORs, PARs and their $95 \%$ CIs. The models included the variables age $(<45,45-60>60$ years), gender, area of residence (10 administrative areas), education level (primary or less, vocational secondary, general secondary and university), alcohol and tobacco consumption (never use of tobacco and alcohol as reference, tobacco but never alcohol use (tobacco alone), alcohol but never tobacco use (alcohol alone) and tobacco and alcohol use (joint effect)), BMI two years before the interview $\left(<25 \mathrm{~kg} \cdot \mathrm{m}^{-2} / \geq\right.$ $25 \mathrm{~kg} \cdot \mathrm{m}^{-2}$ ), family history of HNC in first degree relatives (yes/no), personal history of oral candidiasis (yes/no) and tea drinking (never/ever). The choice of adjusting for these variables was justified by our previous results that showed lower risks of oral cavity cancer in overweight/ obese subjects compared to normal/underweight subjects [9] and in ever tea drinkers compared to never drinkers [11], and higher risks in subject with history of oral candidiasis or family history of HNC compared with subjects without history [10].

Logistic regression models were also used to determine the multiplicative interaction parameter $\Psi$ and the $95 \%$ CI by including the dummy variables ever tobacco consumption, ever alcohol consumption and their product term. An interaction parameter $\Psi$ greater than 1 indicated an interaction between tobacco and alcohol consumption greater than one a multiplicative scale.

PARs and their $95 \%$ CIs were calculated using the 'aflogit' procedure in STATA [29], which estimates the adjusted measures of population attributable fraction from a logistic regression model adapted to case-control studies, on the basis of the method of Greenland and Drescher [30].

Stratified analyses were conducted by gender and age $(<45,45-60,>60$ years). Polytomous regression modes were used to estimate ORs, PARs and $95 \%$ CI by subsite (base of the tongue, mobile tongue, gums, floor of the mouth, hard/soft palate, and other parts of the oral cavity).

All statistical tests were two-sided. Analyses were performed using the Stata Statistical Software release 10.0 (StataCorp 2007, College Station, Texas, USA).

\section{Results}

Men represented more than two thirds of both cases and controls $(78.2 \%$ and $80.6 \%$, respectively). Cases were younger and had lower education level than controls (mean of age 56.8 and 58.5, respectively; university degree $12.3 \%$ and $25.9 \%$, respectively). The most frequent tumour location was the floor of the mouth $(27.7 \%)$, followed by the mobile tongue (23.2\%), the base of the tongue $(18.8 \%)$, other parts of the mouth $(11.5 \%)$ and soft palate $(10.8 \%)$. Gums and hard palate represented only $5.7 \%$ and respectively $2.3 \%$ of cancer locations.

\section{PAR to tobacco and alcohol consumption (Table 1)}

ORs, 95 \% CIs and PARs of oral cavity cancer to alcohol drinking alone, tobacco smoking alone and their joint consumption, and the multiplicative interaction parameter are presented in Table 1 . Alcohol drinking alone was not associated with the risk of oral cavity cancer, while exclusive tobacco smoking and joint consumption of alcohol and tobacco increased the risk. The joint effect was greater than multiplicative (interaction parameter $\Psi>1$ ). PARs were $0.3 \%$ (95 \% CI -3.9-3.9) for alcohol consumption alone, $12.7 \%$ (6.9-18.0) for tobacco consumption alone, $69.9 \%$ (64.4-74.7) for their joint consumption, and $82.9 \%$ (73.8-88.5) for total consumption (alcohol and/or tobacco).

Differences between subsites were observed: the greatest PARs to tobacco consumption alone, joint and total consumption of alcohol and tobacco were observed for floor of the mouth cancer (15.5\% (6.7-23.6) for tobacco consumption alone, $79.6 \%(70.8-85.7)$ for alcohol and tobacco consumption, and $95.6 \%$ (82.3-98.9) for alcohol and/or tobacco consumption). The lowest PARs to tobacco consumption alone, joint and total consumption of alcohol and tobacco were found for gum cancer $(11.1 \%$ (-30.1-39.2) for tobacco consumption alone, $26.2 \%$ 
Table 1 Odds ratios (OR), population attributable risks (PAR) and confidence intervals (95\% Cl) for oral cavity cancer associated with tobacco smoking, alcohol drinking and their joint effect, overall and by subsite, gender and age. ICARE study

\begin{tabular}{|c|c|c|c|c|}
\hline & $\begin{array}{l}\text { Cases } \\
(N=689)\end{array}$ & $\begin{array}{l}\text { Controls } \\
(N=3481)\end{array}$ & OR $(95 \% C l)^{a}$ & $\operatorname{PAR}(95 \% \mathrm{Cl})^{\mathrm{a}}$ \\
\hline \multicolumn{5}{|l|}{ Oral cavity overall } \\
\hline None consumption & 37 & 926 & reference & \\
\hline Alcohol alone & 14 & 297 & $1.1(0.4-2.6)$ & $0.3 \%(-3.9-3.9)$ \\
\hline Tobacco alone & 135 & 1189 & $3.2(1.9-5.3)$ & $12.7 \%(6.9-18.0)$ \\
\hline Tobacco and alcohol & 486 & 1040 & $17.3(10.6-28.3)$ & $69.9 \%(64.4-74.7)$ \\
\hline Total (Alcohol and/or tobacco) & & & $\psi=5.2(1.9-13.8)$ & $82.9 \%(73.8-88.5)$ \\
\hline \multicolumn{5}{|l|}{ By subsite } \\
\hline \multicolumn{5}{|l|}{ Base of tongue } \\
\hline None consumption & 5 & 926 & reference & \\
\hline Alcohol alone & 5 & 297 & $0.8(0.1-7.3)$ & $--^{* *}$ \\
\hline Tobacco alone & 28 & 1189 & $3.3(1.1-9.6)$ & $14.5 \%(0.6-26.5)$ \\
\hline Tobacco and alcohol & 90 & 1040 & $13.1(4.6-37.3)$ & $65.4 \%(49.1-76.5)$ \\
\hline Total (Alcohol and/or tobacco) & & & $\psi=4.8(0.5-46.1)$ & 79.6 \% (50.6-91.6) \\
\hline \multicolumn{5}{|l|}{ Mobile tongue } \\
\hline None consumption & 16 & 926 & reference & \\
\hline Alcohol alone & 3 & 297 & $0.6(0.1-4.7)$ & $--^{* *}$ \\
\hline Tobacco alone & 40 & 1189 & $3.1(1.3-7.3)$ & $16.5 \%(3.5-27.7)$ \\
\hline Tobacco and alcohol & 100 & 1040 & $12.0(5.1-28.5)$ & $60.1 \%(46.1-70.5)$ \\
\hline Total (Alcohol and/or tobacco) & & & $\psi=6.9(0.8-60.5)$ & 75.7 \% (51.3-87.9) \\
\hline \multicolumn{5}{|l|}{ Gum } \\
\hline None consumption & 5 & 926 & reference & \\
\hline Alcohol alone & 2 & 297 & $0.8(0.1-8.0)$ & $--^{* *}$ \\
\hline Tobacco alone & 12 & 1189 & $1.5(0.4-5.4)$ & $11.1 \%(-30.1-39.2)$ \\
\hline Tobacco and alcohol & 18 & 1040 & $2.6(0.7-9.6)$ & $26.2 \%(-13.9-52.2)$ \\
\hline Total (Alcohol and/or tobacco) & & & $\psi=2.0(0.2-23.4)$ & $36.4 \%(-62.3-75.0)$ \\
\hline \multicolumn{5}{|l|}{ Floor of the mouth } \\
\hline None consumption & 2 & 926 & reference & \\
\hline Alcohol alone & 2 & 297 & $2.4(0.2-27.7)$ & $0.5 \%(-5.8-6.4)$ \\
\hline Tobacco alone & 33 & 1189 & $11.1(2.5-48.7)$ & $15.5 \%(6.7-23.6)$ \\
\hline Tobacco and alcohol & 146 & 1040 & $88.1(20.3-381.8)$ & $79.6 \%$ (70.8-85.7) \\
\hline Total (Alcohol and/or tobacco) & & & $\psi=3.3(0.3-38.3)$ & $95.6 \%$ (82.3-98.9) \\
\hline \multicolumn{5}{|l|}{ Soft palate } \\
\hline None consumption & 4 & 926 & reference & \\
\hline Alcohol alone & 0 & 297 & not estimated & \\
\hline Tobacco alone & 11 & 1189 & $2.0(0.5-8.2)$ & $7.2 \%(-9.4-21.3)$ \\
\hline Tobacco and alcohol & 57 & 1040 & $17.5(4.7-65.3)$ & $75.1 \%(55.1-86.1)$ \\
\hline Total (Alcohol and/or tobacco) & & & $\Psi$ not estimated & $82.3 \%$ (44.9-94.3) \\
\hline \multicolumn{5}{|l|}{ Other parts of the mouth } \\
\hline None consumption & 5 & 926 & reference & \\
\hline Alcohol alone & 2 & 297 & $4.4(0.6-34.1)$ & $3.4 \%(-6.6-12.5)$ \\
\hline Tobacco alone & 10 & 1189 & $2.2(0.4-12.8)$ & $4.9 \%(-8.5-16.6)$ \\
\hline
\end{tabular}


Table 1 Odds ratios (OR), population attributable risks (PAR) and confidence intervals (95\% Cl) for oral cavity cancer associated with tobacco smoking, alcohol drinking and their joint effect, overall and by subsite, gender and age. ICARE study (Continued)

\begin{tabular}{|c|c|c|c|c|}
\hline Tobacco and alcohol & 61 & 1040 & $27.7(5.7-135.1)$ & $79.3 \%(59.9-89.2)$ \\
\hline Total (Alcohol and/or tobacco) & & & $\psi=2.8(0.3-26.5)$ & $87.6 \%(50.1-96.9)$ \\
\hline \multicolumn{5}{|l|}{ By gender } \\
\hline \multicolumn{5}{|l|}{ Male } \\
\hline None consumption & 11 & 482 & reference & \\
\hline Alcohol alone & 9 & 247 & $0.7(0.2-2.3)$ & $-{ }^{* *}$ \\
\hline Tobacco alone & 94 & 967 & $2.7(1.3-5.4)$ & $9.8 \%(3.0-16.1)$ \\
\hline Tobacco and alcohol & 431 & 1008 & $13.2(6.8-25.5)$ & $74.0 \%(66.5-79.9)$ \\
\hline Total (Alcohol and/or tobacco) & & & $\psi=7.2(2.1-24.8)$ & $83.3 \%(68.8-91.1)$ \\
\hline \multicolumn{5}{|l|}{ Female } \\
\hline None consumption & 26 & 444 & reference & \\
\hline Alcohol alone & 5 & 50 & $1.4(0.3-7.1)$ & $0.9 \%(-10.6-11.1)$ \\
\hline Tobacco alone & 41 & 222 & $3.6(1.7-7.8)$ & $22.4 \%(6.8-35.5)$ \\
\hline Tobacco and alcohol & 55 & 32 & $41.9(17.8-98.7)$ & $45.4 \%(32.7-55.6)$ \\
\hline Total (Alcohol and/or tobacco) & & & $\psi=8.0(1.4-46.5)$ & $68.7 \%(49.4-80.6)$ \\
\hline \multicolumn{5}{|l|}{ By age } \\
\hline \multicolumn{5}{|l|}{$<45$ years } \\
\hline None consumption & 5 & 124 & reference & \\
\hline Alcohol alone & 0 & 24 & not estimated & \\
\hline Tobacco alone & 10 & 207 & $1.6(0.3-8.8)$ & $8.0 \%(-29.8-34.8)$ \\
\hline Tobacco and alcohol & 33 & 62 & $31.5(4.4-123.1)$ & $67.7 \%(41.5-82.1)$ \\
\hline Total (Alcohol and/or tobacco) & & & $\psi$ not estimated & $75.7 \%(20.6-93.9)$ \\
\hline \multicolumn{5}{|l|}{$45-60$ years } \\
\hline None consumption & 15 & 300 & reference & \\
\hline Alcohol alone & 3 & 97 & $0.4(0.1-3.3)$ & $--^{* *}$ \\
\hline Tobacco alone & 66 & 513 & $2.9(1.4-6.0)$ & $10.9 \%(3.5-17.8)$ \\
\hline Tobacco and alcohol & 297 & 399 & $22.1(10.9-44.7)$ & $75.2 \%(68.3-80.5)$ \\
\hline Total (Alcohol and/or tobacco) & & & $\Psi=18.4(2.2-152.3)$ & $85.5 \%(73.4-92.1)$ \\
\hline \multicolumn{5}{|l|}{$>60$ years } \\
\hline None consumption & 17 & 502 & reference & \\
\hline Alcohol alone & 11 & 176 & $2.4(0.8-6.8)$ & $2.5 \%(-3.8-8.4)$ \\
\hline Tobacco alone & 59 & 469 & $5.1(2.3-11.0)$ & $16.8 \%(7.9-24.7)$ \\
\hline Tobacco and alcohol & 156 & 579 & $16.4(7.7-35.1)$ & $62.8 \%(52.7-70.8)$ \\
\hline Total (Alcohol and/or tobacco) & & & $\Psi=1.4(0.4-4.3)$ & $82.1 \%(67.4-90.2)$ \\
\hline
\end{tabular}

**Negative population attributable risk (PAR) $(\mathrm{OR}<1$ and not significant)

ORs and PARs for hard palate were not estimated because of lack of cases in the reference category ( 0 never drinker never smoker)

a Logistic model adjusted for age, gender, area of residence, education level, tobacco and alcohol consumption, BMI two years before the interview, family history of head and neck cancer, history of candidiasis and tea consumption

$\psi=$ alcohol - tobacco interaction term

(-13.9-52.2) for joint consumption of alcohol and tobacco, and $36.4 \%(-62.3-75.0)$ for alcohol and/or tobacco consumption). For the base of the tongue and soft palate, oral subsites generally grouped with the oropharynx, the PARs were similar to that observed for mobile tongue and other parts of the mouth; for example, the total PAR was $79.6 \%$ (50.6-91.6) for base of the tongue, $75.7 \%$ (51.3-87.9) for mobile tongue, $82.3 \%$ (44.9-94.3) for soft palate and $87.6 \%$ (50.196.9) for other parts of the mouth. With respect to the exclusive alcohol drinking, the PARs were low and some negative values were found when the ORs were below 1 for base of the tongue, mobile tongue and gum cancers. 
The PARs were lower in women than in men for both the joint and total consumption of alcohol and tobacco (in women: $45.4 \%, 32.7-55.6$, and $68.7 \%, 49.4-80.6$, respectively; in men: $74.0 \%, 66.5-79.9$, and $83.3 \%, 68.8-$ 91.1, respectively). Concerning the PARs stratified by age, it was difficult to conclude to any difference between subjects younger than 45 compared to subjects aged 45-60 or older because CIs are large and overlapped.

\section{PAR to other risk factors}

ORs, PARs and $95 \%$ CI for oral cavity cancer associated with other risk factors than alcohol and tobacco are presented in Table 2. Around $35 \%$ (25.7-43.6) of oral cavity cancer cases were attributable to a $\mathrm{BMI}<25.0 \mathrm{~kg} \cdot \mathrm{m}^{-2}$. Since the confidence intervals overlapped, it is not possible to conclude to significant differences between subsites. Among men, the corresponding PAR was $39.9 \%$ (30.0-48.3). No association was observed in women between BMI and oral cavity cancer $(\mathrm{OR}=1.1(0.6-2.0))$, leading to a small PAR (4.2\%, -38.4-33.7). No significant differences were observed in PAR stratified by age.

Only few oral cavity cancers were attributable to having a family history of HNC in first degree relatives (5.8\%, 0.6-10.8). No noticeable differences were observed in PAR by subsite or by age. The PARs were $6.8 \%$ in men and $2.1 \%$ in women with overlapping CIs.

Very few oral cancer cases were attributable to a personal history of oral candidiasis $(1.9 \%,-2.1-5.7 \%)$. We did not find any significant difference in PARs stratified by subsite, gender or age.

The PAR associated with never drinking tea was $30.3 \%$ (14.4-43.3). The highest ORs and PARs were observed for soft palate and other parts of the mouth but confidence intervals were large and overlapped and it was difficult to conclude to any difference. The PAR was $38.0 \%$ in men and only $13.9 \%$ in women, confidence intervals overlapping. Analysis stratified by age did not show significant differences in PAR.

\section{PAR to all risk factors combined}

The PAR to all factors combined was around $93 \%$ (95\% CI 88.3-95.6) with the lowest value of $78.5 \%$ (95\% CI 15.2-94.6) for the gum cancer and the highest value of $98.0 \%$ (95 \% CI 91.4-99.5) for the floor of the mouth cancer (Table 3 ). The PARs varied by gender, the studied risk factors explaining $94.3 \%$ (95\% CI 88.4-97.2) of cases in men, and only $74.1 \%$ (95\% CI 47.0-87.3) of them in women, mainly because of differences between the two genders in risks related to tobacco and alcohol consumption. No significant difference in PAR by age was found.

\section{Discussion}

The ICARE study is one of the few studies investigating the PARs of oral cavity cancer to several recognized or suspected risk factors. The PARs should in principle be estimated for risk factors with a proven causal relationship with a cancer/the disease. Nevertheless, we also calculated PARs for several suspected risk factors. Some of these factors (family and medical history) are not modifiable or can hardly be subject to preventive measures. In addition, obviously, it is not possible to recommend a weight gain that was inversely associated with the risk oral cavity cancer, because of the negative consequences on many other diseases. However, the objective here was to assess the impact of each risk factor, prioritize them, and determine the proportion of oral cavity cancers that remains to be possibly explained by other unexplored factors.

Our results have shown that the proportion of risk attributable to tobacco smoking alone was greater than that attributable to alcohol drinking alone. Smoking was an independent risk factor for oral cavity cancer while drinking, in the absence of smoking, conferred little and no significant risk. These results are similar to those reported in other studies [12, 13, 15, 17, 18, 31, 32]. Consistently with the difference in risks associated with smoking or smoking and drinking by subsite found in our study [5] as elsewhere [20-25], we observed differences in the estimates of PARs across oral cavity subsites. Some negative estimates for the PAR to exclusive alcohol drinking were observed. This does not indicate a protective effect of alcohol since the corresponding ORs did not suggest statistically significant inverse associations. We also observed a greater than multiplicative interaction between tobacco and alcohol, consistent with previous studies [13-18].

The proportion of cases attributable to the joint effect of tobacco and alcohol was around $70 \%$, confirming that tobacco and alcohol together explain the majority of oral cavity cancer burden in France. This result is consistent with that reported by one case-control study conducted in Latin America [17], but higher than that observed in an international pooled analysis [15] and a European case-control study [13].

Differences in PARs by gender were observed, particularly with regards to the attributable risks to tobacco and alcohol. The PAR to their joint consumption was higher in men than in women (74.0\% and $45.4 \%$, respectively), consistent with previous studies $[13,15,17]$. This can be explained by the higher proportion of drinkers and/or smokers in men than in women; the prevalence of combined consumption was around $78 \%$ in male cases and only $41 \%$ in female cases. Nevertheless, we cannot rule out more underreporting of these expositions among women than among men, especially for alcohol drinking, which is less socially accepted among women.

Conversely to the available studies $[13,15,19]$, we did not find a lower proportion of oral cavity cancers attributable to alcohol and tobacco consumption in subjects 
Table 2 Odds ratios (OR), population attributable risks (PAR) and confidence intervals (95\% Cl) for oral cavity cancer associated with body mass index, family history of head and neck cancer, history of oral candidiasis, and tea consumption, overall and by subsite, gender and age. ICARE study

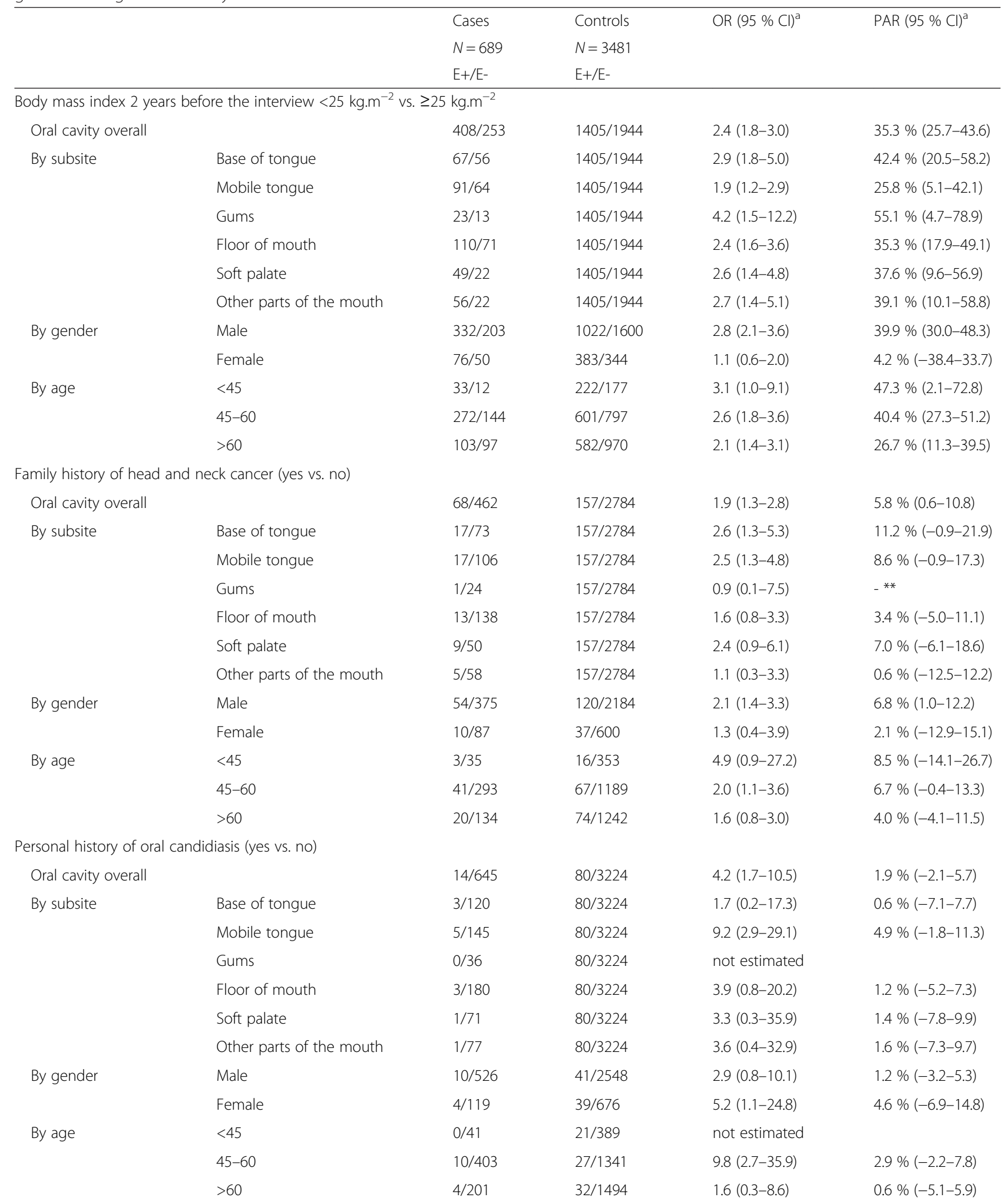


Table 2 Odds ratios (OR), population attributable risks (PAR) and confidence intervals (95\% Cl) for oral cavity cancer associated with body mass index, family history of head and neck cancer, history of oral candidiasis, and tea consumption, overall and by subsite, gender and age. ICARE study (Continued)

\begin{tabular}{|c|c|c|c|c|c|}
\hline \multicolumn{6}{|c|}{ Tea consumption (never vs. ever) } \\
\hline Oral cavity overall & & $443 / 150$ & 2025/1334 & $1.7(1.3-2.2)$ & $30.3 \%(14.4-43.3)$ \\
\hline \multirow[t]{6}{*}{ By subsite } & Base of tongue & $80 / 37$ & 2025/1334 & $1.0(0.6-1.7)$ & $0.1 \%(-44.6-30.9)$ \\
\hline & Mobile tongue & $102 / 36$ & $2025 / 1334$ & $1.5(0.9-2.5)$ & $23.2 \%(-13.2-47.9)$ \\
\hline & Gums & $20 / 10$ & 2025/1334 & $1.9(0.6-6.0)$ & $36.1 \%(-57.3-74.0)$ \\
\hline & Floor of mouth & $128 / 38$ & 2025/1334 & $1.5(0.9-2.3)$ & $23.6 \%(-7.1-45.4)$ \\
\hline & Soft palate & $48 / 13$ & $2025 / 1334$ & $4.3(1.7-10.7)$ & $67.5 \%(29.3-85.0)$ \\
\hline & Other parts of the mouth & $55 / 13$ & $2025 / 1334$ & $4.2(1.6-11.1)$ & $67.6 \%(24.1-86.2)$ \\
\hline \multirow[t]{2}{*}{ By gender } & Male & $377 / 99$ & $1692 / 928$ & $1.9(1.4-2.6)$ & $38.0 \%(21.3-51.2)$ \\
\hline & Female & $66 / 51$ & $333 / 406$ & $1.3(0.7-2.4)$ & $13.9 \%(-18.1-37.3)$ \\
\hline \multirow[t]{3}{*}{ By age } & $<45$ & $231 / 172$ & $28 / 14$ & $2.3(0.7-7.8)$ & $45.7 \%(-37.1-78.5)$ \\
\hline & $45-60$ & $848 / 561$ & $284 / 93$ & $1.4(0.9-2.1)$ & $22.2 \%(-3.22-41.2)$ \\
\hline & $>60$ & $946 / 601$ & $131 / 43$ & $1.9(1.3-3.1)$ & $38.2 \%(13.0-56.1)$ \\
\hline
\end{tabular}

**Negative population attributable risk (OR $<1$ and not significant)

aLogistic model adjusted for age, gender, area of residence, education level, tobacco and alcohol consumption, BMI 2 years before the interview, family history of head and neck cancer, history of candidiasis and tea consumption

E+ exposed subject/E- non-exposed subject to a risk factor

younger than 45 , probably because of the small size of this category compared to the older age groups.

In our study, PAR of oral cavity cancer to family history of $\mathrm{HNC}$ was around $6 \%$, greater than that reported for HNC overall in the pooled analysis within INHANCE Consortium (around $2 \%$ ) [26]. This difference may be explained by the higher percentage of subjects exposed to a family history of HNC in our study $(9.9 \%$ in cases and $4.5 \%$ in controls) than in the pooled analysis $(3.6 \%$ in cases and $1.8 \%$ in controls).

Table 3 Population attributable risks (PAR) and their confidence intervals $(95 \%$ Cl) for oral cavity cancer associated with all risk factors, overall, by subsite, gender and age. ICARE study

\begin{tabular}{lll}
\hline & & PAR $(95 \% \mathrm{Cl})^{\mathrm{a}}$ \\
\hline Oral cavity overall & & $92.8 \%(88.3-95.6)$ \\
\cline { 2 - 2 } & Base subsite & $89.9 \%(71.6-96.4)$ \\
& Mobile tongue & $88.1 \%(72.4-94.9)$ \\
& Gums & $78.5 \%(15.2-94.6)$ \\
& Floor of mouth & $98.0 \%(91.4-99.5)$ \\
& Soft palate & $96.8 \%(86.3-99.3)$ \\
By gender & Other parts of the mouth & $97.5 \%(86.9-99.5)$ \\
& Male & $94.3 \%(88.4-97.2)$ \\
By age & Female & $74.1 \%(47.0-87.3)$ \\
& $<45$ & $94.3 \%(59.4-99.2)$ \\
& $45-60$ & $93.7 \%(87.3-96.9)$ \\
& $>60$ & $92.4 \%(84.2-96.4)$ \\
\hline
\end{tabular}

aLogistic model adjusted for age, gender, area of residence, education level, tobacco and alcohol consumption, BMI 2 years before the interview, family history of head and neck cancer, history of candidiasis and tea consumption
Low versus high BMI and never versus ever consumption of tea appear to be responsible for a significant number of oral cavity cancers, especially in men. The possible role of body fat in the distribution of the lipophilic carcinogens derived from tobacco smoke [33] and the implication of tea polyphenols in the apoptosis and the inhibition of the growth of oral carcinoma cells [34, 35] might explain these findings.

Approximately $93 \%$ of cases of oral cavity cancer overall, $94 \%$ in men and only $74 \%$ in women, are explained by all the studied factors. This leaves about $7 \%$ of cases to be explained by other risk factors that we have not been able to take into account, of which $6 \%$ in men and $26 \%$ in women. This result emphasizes the role of other risk factors in women, such as human papillomavirus (HPV) infection, diet, hormonal factors or specific genetic factors of cancer susceptibility.

Strengths of our study are the multicenter design and the study size that allowed us to perform stratified analyses by anatomic subsite, gender and age.

Some limitations of our study exist. The subjects selfreported their own consumption of tobacco, alcohol and tea, anthropometric measurements, medical and family history. Thereby, recall bias could not be ruled out and it is possible that the cases had a higher motivation than the controls to recall tobacco and alcohol consumption as well as medical and family history, known as potential risk factors of cancer. Nevertheless, we do not think that underreporting of alcohol consumption may explain its negligible impact because alcohol drinking is socially accepted in France. In France, only 8.4 \% of people reported never having drunk alcohol [36], a proportion close to that 
of never drinkers among our controls (8.6\%). We think that recall bias for BMI and tea drinking would be nondifferential among cases and controls, since these factors are not generally known to be related to oral cavity cancer. If present, this bias would tend to attenuate the associations with cancer risk. In addition, many studies have shown that subjects in case-control studies are able to accurately self-report family history of common types of cancer among first-degree relatives $[37,38]$ and tea consumption [39].

Information about other suspected or known risk factors for oral cavity cancer such as HPV infection or diet was not collected in our study and residual confounding cannot be excluded. HPV infection is a recognized risk factor for base of the tongue and tonsils cancers, but less for the other HNC [40]. However, adjustment for HPV seemed to have only minor effects on the estimated ORs for alcohol and tobacco [41-43]. In addition, an International Agency for Cancer Research report on attributable causes of cancer in France estimated the PAR of oral cavity and oropharynx cancers to HPV infection low and similar in both genders (6.7 \%) [44]. A diet rich in fruits and vegetables, generally associated with lower body size, have a protective effect against HNC [45-47]. Thus, confounding by diet is unlikely to explain the inverse association between BMI and oral cavity cancer that we found, although it could reduce the precision of the ORs. Also, we think that the lack of information on HPV and diet could not explain the differences in PARs that we observed.

\section{Conclusion}

While we did not observe an independent effect of alcohol on oral cavity cancer risk in our study, concurrent smoking and drinking are responsible for the majority of oral cavity cancers, especially among men. In terms of public health, this study suggests that a reduction of combined tobacco and alcohol consumption could result in a significant decrease of oral cancer. Ninety-three percent of cases overall and $94 \%$ in men are explained by known or suspected risk factors. However, a substantial proportion of oral cavity cancer among women $(26 \%)$ cannot be attributed to either established or suspected risk factors. Still unexplored factors conferring oral cancer risk among women remain to be clarified by future studies.

\footnotetext{
Abbreviations

PAR: population attributable risk; OR: odds ratio; 95 \% Cl: 95 \% confidence interval; HNC: head and neck cancer; BMl: body mass index; HPV: human papillomavirus; INHANCE consortium: International Head and Neck Cance Epidemiology Consortium; ICARE study: Investigation of occupational and environmental CAuses of REspiratory cancers study; ICD: International Classification of Diseases.
}

\section{Competing interest}

The authors declare that they have no conflict of interest.

\section{Authors' contributions}

$\mathrm{DL}$ and LR conceived and designed the current study and drafted the manuscript; LR and DC analyzed the data; DL and IS, the principal investigators of the ICARE study, conceived this study, designed the questionnaire, and coordinated the original collection of the data. DC and LLB contributed to data collection and quality control; GM and DC contributed to the statistical analysis. All authors participated to data interpretation and critical revision of the manuscript. All authors read and approved the final manuscript.

\section{Acknowledgements}

ICARE study was supported by French National Research Agency (ANR); French Agency for Food, Environmental and Occupational Health and Safety (ANSES); French Institute for Public Health Surveillance (InVS); Foundation for Medical Research (FRM); Foundation of France, Association for Research on Cancer (ARC); Ministry of Labour (Direction Générale du Travail); Ministry of Health (Direction Générale de la Santé). L. Radoï was supported for this work by the French National Cancer Institute (INCa), grant n²009-349.

Icare Study Group

French cancer registries: Michel Velten (Bas-Rhin); Anne-Valérie Guizard (Calvados); Arlette Danzon, Anne-Sophie Woronoff (Doubs); Antoine Buemi, Émilie Marrer (Haut-Rhin); Brigitte Trétarre (Hérault); Marc Colonna, Patricia Delafosse (Isère); Paolo Bercelli, Florence Molinie (Loire-Atlantique - Vendée) Simona Bara (Manche); Bénédicte Lapôtre-Ledoux, Nicole Raverdy (Somme) University Lyon 1, UMRESTTE, Lyon, France: Joëlle Févotte

French Institute for Public Health Surveillance, Department of Occupational Health, Saint Maurice, France: Corinne Pilorget

Inserm UMR 1018, CESP, Villejuif, France: Sylvie Cénée, Oumar Gaye, Farida Lamkarkach, Loredana Radoï, Marie Sanchez, Isabelle Stücker

Inserm UMS 011, Villejuif, France: Matthieu Carton, Diane Cyr, Annie Schmaus Inserm UMR_S 1136, Paris, France: Gwenn Menvielle

Inserm UMR 1085, IRSET, Pointe-à-Pitre, France: Danièle Luce

\section{Author details}

${ }^{1}$ INSERM UMRS 1018, Environmental Epidemiology of Cancer, Centre for research in Epidemiology and Population Health, 16 Avenue Paul Vaillant Couturier, 94807 Villejuif Cedex, France. ${ }^{2}$ Oral Medicine and Oral Surgery Department, Paris Descartes University, Montrouge, France. ${ }^{3}$ INSERM, UMR_S 1136, Pierre Louis Institute of Epidemiology and Public Health, Paris, France. ${ }^{4}$ Sorbonne Universités, UPMC Univ Paris 6, UMR_S 1136, Pierre Louis Institute of Epidemiology and Public Health, Paris, France. ${ }^{5}$ INSERM UMS 011, Villejuif, France. ${ }^{6}$ Versailles St-Quentin University, Versailles, France. ${ }^{7}$ Registre du Cancer de la Somme, CHU Amiens, EA Inserm - DGS, EA 4666, Amiens, France. ${ }^{8}$ Paris Sud University, Kremlin-Bicêtre, France. ${ }^{9}$ INSERM U 1085, IRSET, Pointe-à-Pitre, French West Indies, Rennes, France. ${ }^{10}$ University of Rennes 1, Rennes, France.

Received: 4 May 2015 Accepted: 23 October 2015

Published online: 31 October 2015

\section{References}

1. World Health Organization. International Classification of Diseases 10th Revision. Geneva: World Health Organization; 2007.

2. Ferlay J, Shin HR, Bray F, Forman D, Mathers C, Parkin DM. Estimates of worldwide burden of cancer in 2008: GLOBOCAN 2008. Int J Cancer. 2010;127:2893-917.

3. de Camargo CM, Voti L, Guerra-Yi M, Chapuis F, Mazuir M, Curado MP. Ora cavity cancer in developed and in developing countries: population-based incidence. Head Neck. 2010;32:357-67.

4. Ligier K, Belot A, Launoy G, Velten M, Bossard N, Iwaz J, et al. Descriptive epidemiology of upper aerodigestive tract cancers in France: incidence over 1980-2005 and projection to 2010. Oral Oncol. 2011:47:302-7.

5. Radoi L, Paget-Bailly S, Cyr D, Papadopoulos A, Guida F, Schmaus A, et al. Tobacco smoking, alcohol drinking and risk of oral cavity cancer by subsite: results of a French population-based case-control study, the ICARE study. Eur J Cancer Prev. 2012;22:268-76.

6. Andre K, Schraub S, Mercier M, Bontemps P. Role of alcohol and tobacco in the aetiology of head and neck cancer: a case-control study in the Doubs region of France. Eur J Cancer B Oral Oncol. 1995;31B:301-9.

7. Brugere J, Guenel P, Leclerc A, Rodriguez J. Differential effects of tobacco and alcohol in cancer of the larynx, pharynx, and mouth. Cancer. 1986;57:391-5. 
8. Leclerc A, Brugere J, Luce D, Point D, Guenel P. Type of alcoholic beverage and cancer of the upper respiratory and digestive tract. Eur J Cancer Clin Oncol. 1987;23:529-34

9. Radoi L, Paget-Bailly S, Cyr D, Papadopoulos A, Guida F, Tarnaud C, et al. Body mass index, body mass change, and risk of oral cavity cancer: results of a large population-based case-control study, the ICARE study. Cancer Causes Control. 2013;24:1437-48.

10. Radoi L, Paget-Bailly S, Guida F, Cyr D, Menvielle G, Schmaus A, et al. Family history of cancer, personal history of medical conditions and risk of oral cavity cancer in France: the ICARE study. BMC Cancer. 2013;13:560.

11. Radoi L, Paget-Bailly S, Menvielle G, Cyr D, Schmaus A, Carton M, et al. Tea and coffee consumption and risk of oral cavity cancer: Results of a large population-based case-control study, the ICARE study. Cancer Epidemiol. 2013;37:284-9

12. Petti S, Mohd M, Scully C. Revisiting the association between alcohol drinking and oral cancer in nonsmoking and betel quid non-chewing individuals. Cancer Epidemiol. 2012;36:e1-6.

13. Anantharaman D, Marron M, Lagiou P, Samoli E, Ahrens W, Pohlabeln H, et al. Population attributable risk of tobacco and alcohol for upper aerodigestive tract cancer. Oral Oncol. 2011;47:725-31.

14. Castellsague X, Quintana MJ, Martinez MC, Nieto A, Sanchez MJ, Juan A, et al. The role of type of tobacco and type of alcoholic beverage in oral carcinogenesis. Int J Cancer. 2004;108:741-9.

15. Hashibe M, Brennan P, Chuang SC, Boccia S, Castellsague X, Chen C, et al. Interaction between tobacco and alcohol use and the risk of head and neck cancer: pooled analysis in the International Head and Neck Cancer Epidemiology Consortium. Cancer Epidemiol Biomarkers Prev. 2009;18:541-50.

16. Schildt EB, Eriksson M, Hardell $L$, Magnuson A. Oral snuff, smoking habits and alcohol consumption in relation to oral cancer in a Swedish casecontrol study. Int J Cancer. 1998;77:341-6.

17. Szymanska K, Hung RJ, Wunsch-Filho V, Eluf-Neto J, Curado MP, Koifman S, et al. Alcohol and tobacco, and the risk of cancers of the upper aerodigestive tract in Latin America: a case-control study. Cancer Causes Control. 2011;22:1037-46

18. Ferreira Antunes JL, Toporcov TN, Biazevic MG, Boing AF, Scully C, Petti S. Joint and independent effects of alcohol drinking and tobacco smoking on oral cancer: a large case-control study. PLoS One. 2013;8, e68132.

19. Toporcov TN, Znaor A, Zhang ZF, Yu GP, Winn DM, Wei Q, et al. Risk factors for head and neck cancer in young adults: a pooled analysis in the INHANCE consortium. Int J Epidemiol. 2015;44:169-85.

20. Barasch A, Morse DE, Krutchkoff DJ, Eisenberg E. Smoking, gender, and age as risk factors for site-specific intraoral squamous cell carcinoma. A case-series analysis. Cancer. 1994:73:509-13.

21. Boffetta P, Mashberg A, Winkelmann R, Garfinkel L. Carcinogenic effect of tobacco smoking and alcohol drinking on anatomic sites of the oral cavity and oropharynx. Int J Cancer. 1992;52:530-3.

22. Jovanovic A, Schulten EA, Kostense PJ, Snow GB, van der Waal I. Tobacco and alcohol related to the anatomical site of oral squamous cell carcinoma. J Oral Pathol Med. 1993:22:459-62.

23. Llewelyn J, Mitchell R. Smoking, alcohol and oral cancer in south east Scotland: a 10-year experience. Br J Oral Maxillofac Surg. 1994;32:146-52.

24. Macfarlane GJ, Zheng T, Marshall JR, Boffetta P, Niu S, Brasure J, et al. Alcohol, tobacco, diet and the risk of oral cancer: a pooled analysis of three case-control studies. Eur J Cancer B Oral Oncol. 1995;31B:181-7.

25. Spitz MR, Fueger JJ, Goepfert H, Hong WK, Newell GR. Squamous cell carcinoma of the upper aerodigestive tract. A case comparison analysis. Cancer. 1988;61:203-8.

26. Negri E, Boffetta P, Berthiller J, Castellsague $X$, Curado MP, Dal ML, et al. Family history of cancer: pooled analysis in the International Head and Neck Cancer Epidemiology Consortium. Int J Cancer. 2009;124:394-401.

27. Luce D, Stucker I, Icare Study Group. Investigation of occupational and environmental causes of respiratory cancers (ICARE): a multicenter, populationbased case-control study in France. BMC Public Health. 2011;11:928.

28. World Health Organization. International Classification of Diseases for Oncology 3rd Revision. Geneva: World Health Organization; 2000.

29. Brady A. sbe21 - Adjusted population attributable fractions from logistic regression. Stata Technical Bulletin. 1998;42:8-12.

30. Greenland S, Drescher K. Maximum likelihood estimation of the attributable fraction from logistic models. Biometrics. 1993;49:865-72.

31. Hashibe M, Brennan P, Benhamou S, Castellsague X, Chen C, Curado MP, et al. Alcohol drinking in never users of tobacco, cigarette smoking in never drinkers, and the risk of head and neck cancer: pooled analysis in the International Head and Neck Cancer Epidemiology Consortium. J Natl Cancer Inst. 2007:99:777-89.

32. Petti S, Masood M, Messano GA, Scully C. Alcohol is not a risk factor for oral cancer in nonsmoking, betel quid non-chewing individuals. A meta-analysis update. Ann Ig. 2013;25:3-14.

33. Godschalk RW, Feldker DE, Borm PJ, Wouters EF, van Schooten FJ. Body mass index modulates aromatic DNA adduct levels and their persistence in smokers. Cancer Epidemiol Biomarkers Prev. 2002;11:790-3.

34. Hsu SD, Singh BB, Lewis JB, Borke JL, Dickinson DP, Drake $L$, et al. Chemoprevention of oral cancer by green tea. Gen Dent. 2002;50:140-6.

35. Schwartz JL, Baker V, Larios E, Chung FL. Molecular and cellular effects of green tea on oral cells of smokers: a pilot study. Mol Nutr Food Res. 2005;49:43-51

36. Legleye $\mathrm{S}$, Rosilio T, Nahon T. Alcoolisation, un phénomène complexe. In: Guilbert P, Gautier A, editors. Baromètre santé 2005, Editions INPES. 2005

37. Kerber RA, Slattery ML. Comparison of self-reported and database-linked family history of cancer data in a case-control study. Am J Epidemiol. 1997; 146:244-8

38. Love RR, Evans AM, Josten DM. The accuracy of patient reports of a family history of cancer. J Chronic Dis. 1985;38:289-93.

39. Ferraroni M, Tavani A, Decarli A, Franceschi S, Parpinel M, Negri E, et al. Reproducibility and validity of coffee and tea consumption in Italy. Eur J Clin Nutr. 2004:58:674-80.

40. Hobbs CG, Sterne JA, Bailey M, Heyderman RS, Birchall MA, Thomas SJ. Human papillomavirus and head and neck cancer: a systematic review and meta-analysis. Clin Otolaryngol. 2006;31:259-66.

41. Applebaum KM, Furniss CS, Zeka A, Posner MR, Smith JF, Bryan J, et al. Lack of association of alcohol and tobacco with HPV16-associated head and neck cancer. J Natl Cancer Inst. 2007;99:1801-10.

42. Rosenquist K, Wennerberg J, Schildt EB, Bladstrom A, Hansson BG, Andersson G. Use of Swedish moist snuff, smoking and alcohol consumption in the aetiology of oral and oropharyngeal squamous cell carcinoma. A population-based case-control study in southern Sweden. Acta Otolaryngol. 2005:125:991-8.

43. Hansson BG, Rosenquist K, Antonsson A, Wennerberg J, Schildt EB, Bladstrom A, et al. Strong association between infection with human papillomavirus and oral and oropharyngeal squamous cell carcinoma: a population-based case-control study in southern Sweden. Acta Otolaryngol. 2005;125:1337-44.

44. World Health Organization. International Agency for Research on Cancer. Attributable causes of cancer in France in the year 2000. IARC working group reports. 2007;3:46.

45. Freedman ND, Park Y, Subar AF, Hollenbeck AR, Leitzmann MF, Schatzkin A, et al. Fruit and vegetable intake and head and neck cancer risk in a large United States prospective cohort study. Int J Cancer. 2008;122:2330-6.

46. Lagiou P, Talamini R, Samoli E, Lagiou A, Ahrens W, Pohlabeln H, et al. Diet and upper-aerodigestive tract cancer in Europe: the ARCAGE study. Int Cancer. 2009;124:2671-6

47. Pavia M, Pileggi C, Nobile CG, Angelillo IF. Association between fruit and vegetable consumption and oral cancer: a meta-analysis of observational studies. Am J Clin Nutr. 2006;83:1126-34.

\section{Submit your next manuscript to BioMed Central and take full advantage of:}

- Convenient online submission

- Thorough peer review

- No space constraints or color figure charges

- Immediate publication on acceptance

- Inclusion in PubMed, CAS, Scopus and Google Scholar

- Research which is freely available for redistribution 